\title{
Large excavations and multi-disciplinary studies in deep underground laboratories
}

\author{
Joseph S.Y. Wang \\ Lawrence Berkeley National Laboratory, Berkeley, CA, USA
}

\begin{abstract}
Since 2013, we have gathered some information on excavations recently completed, renovated, or planned in Asia, Europe, North and South America. In this review, we presented what we learned on both the large excavations and on multi-disciplinary studies. Large excavations in physics laboratories are driven by the needs associated with designing next generation of experiments to detect rare events. Some existing physics laboratories are interested to use available spaces for geo-sciences studies, including microbiological research for deep life. Summary of recent progress will be discussed.
\end{abstract}

\section{Commission on Underground Research Laboratory Networking}

The International Society for Rock Mechanics (ISRM) has the Commission on Underground Research Laboratory (URL) Networking established in 2011. The scope includes reviews of radioactive waste repository research URLs, deep physics facilities, and general energy and environmental studies. Among URLs reviewed, LSBB is unique in its focus on inter-disciplinary research. We note that there are growing interests to multi-disciplinary studies in some other underground facilities. In our next phase for the ISRM URL Networking Committee, we plan to further gather information from each existing and planned URLs, physics deep facilities, and general underground studies for a publication of case histories. Examples of large excavations designed for physics experiments are given below.

\section{Examples of large excavations and multi-disciplinary studies}

China JinPing Laboratory: Figure 1 is a scheme of the second phase for the China JinPing Laboratory (CJPL-II) [1]. Eight new halls are planned to be excavated in 2015, with each hall $12 \mathrm{~m}$ wide, $10 \mathrm{~m}$ high, and over $40 \mathrm{~m}$ long, from a by-pass tunnel of one of the JinPing traffic tunnels. The total volume of CJPL-II is expected to be $96,000 \mathrm{~m}^{3}$, in comparison with $4,000 \mathrm{~m}^{3}$ for CJPL-I. JinPing tunnels have the laboratory spaces located under 2,450 m overburden and is the world deepest physics underground laboratory with horizontal access. Next generation dark matter search experiments and other international studies are expected to be implemented at CJPL-II. We also propose that [SQUID] ${ }^{2}$ for monitoring seismically induced electromagnetic global signals and SIMPLE dark matter search experiment at LSBB will be considered at CJPL-II.

This is an Open Access article distributed under the terms of the Creative Commons Attribution License 4.0, which permits unrestricted use, distribution, and reproduction in any medium, provided the original work is properly cited. 


\section{E3S Web of Conferences}

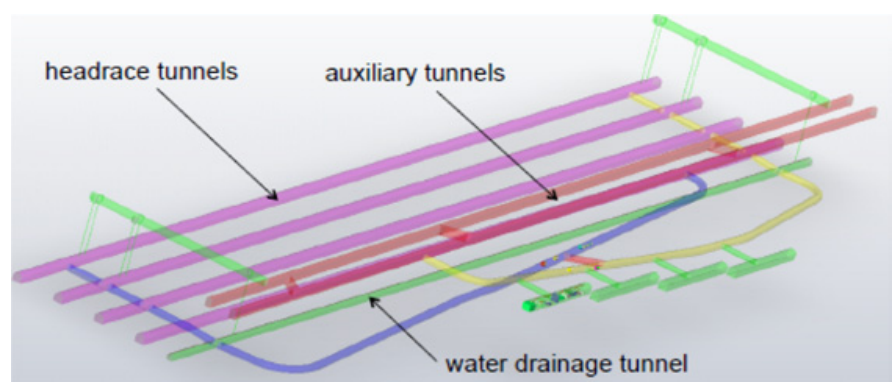

Figure 1. 3-D prospective of CJPL-II in relation to the JinPing tunnel complex, from [1, Fig. 3b].

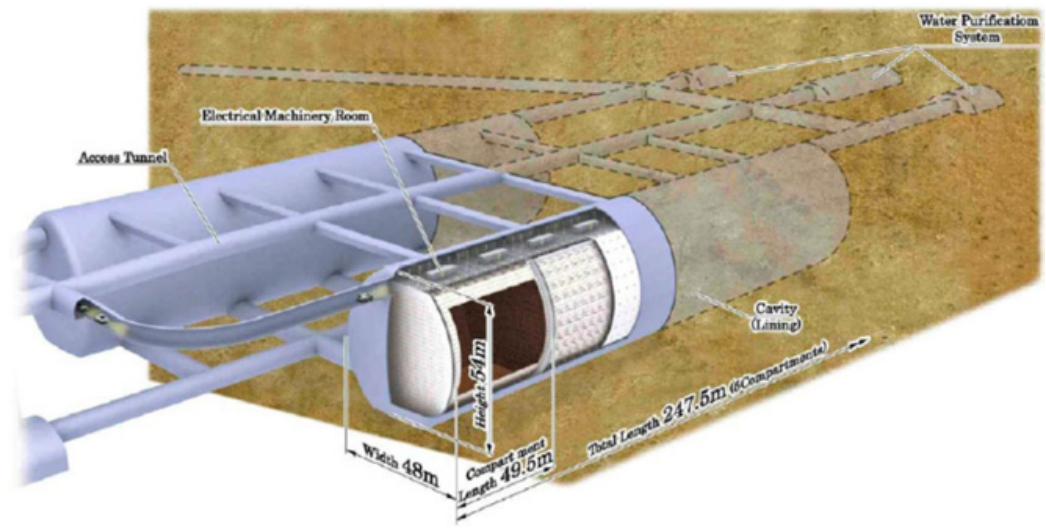

Figure 2. Current design of Hyper- KAMIOKANDE experiment [2, slide 1].

Table 1. Comparison of Finland's Pyhasalmi mine man-made caverns with other underground caverns [3, slide 11].

\begin{tabular}{|c|c|c|c|c|c|}
\hline Site & Country & span & length & height & depth \\
\hline LBNO LIQUID ARGON, & Finland & $64 \mathrm{~m}$ & $103 \mathrm{~m}$ & $51 \mathrm{~m}$ & $1450 \mathrm{~m}$ ÜROCKPLAN \\
\hline Gjøvik Olympic Cavern Hall & Norway & $61 \mathrm{~m}$ & $91 \mathrm{~m}$ & $25 \mathrm{~m}$ & $40 \mathrm{~m}$ \\
\hline Tytyri Mine, chalk mine museum & Finland & $60 \mathrm{~m}$ & & & $110 \mathrm{~m}$ \\
\hline Hyper-Kamiokande, neutrino det. & Japan & $48 m$ & $248 m$ & $54 m$ & $700 \mathrm{~m}$ \\
\hline LIQUID SCINTILLATOR, & Finland & $44 m$ & $71 m$ & $120 \mathrm{~m}$ & $1450 \mathrm{~m}$ âROCKPLAN \\
\hline Salmisaari coal storage silos & Finland & $42 \mathrm{~m}$ & $42 \mathrm{~m}$ & $65 \mathrm{~m}$ & $50 \mathrm{~m}$ aROCKPLAN \\
\hline Leppävirta, cross country ski hall & Finland & $41 \mathrm{~m}$ & $100 \mathrm{~m}$ & $10 \mathrm{~m}$ & $15 \mathrm{~m}$ טROCKPLA \\
\hline Super- Kamiokande, neutrino de & t. Japan & $40 \mathrm{~m}$ & $40 \mathrm{~m}$ & $55 \mathrm{~m}$ & $1000 \mathrm{~m}$ \\
\hline Vihanti mine & Finland & $40 \mathrm{~m}$ & & & $180 \mathrm{~m}$ \\
\hline
\end{tabular}

Japan's Hyper-KAMIOKANDE Design: Figure 2 is the current design of the HyperKAMIOKANDE experiment for Japan. This is the largest experiment planned worldwide, with currently a twin-cavern configuration, with each $48 \mathrm{~m}$ wide, $54 \mathrm{~m}$ high, and $247.5 \mathrm{~m}$ long, and total volume for a mega ton water Cherenkov detector. The current location considered is in the Tochibora Mine [2]. There is a plan in 2014-2015 to characterize a deeper location of $1 \mathrm{~km}$ at the Mozumi Mine.

Finland's Pyhasalmi Laboratory Hall Design: Table 1 compares the cavern dimension of the planned liquid argon experiment in Finland's Pyhasalmi mine with other man-made caverns worldwide. This is associated with the LAGUNA project Long Baseline Neutrino Observatory (LBNO) in Europe with a neutrino beam from CERN to different candidate sites [3]. 
Final Design

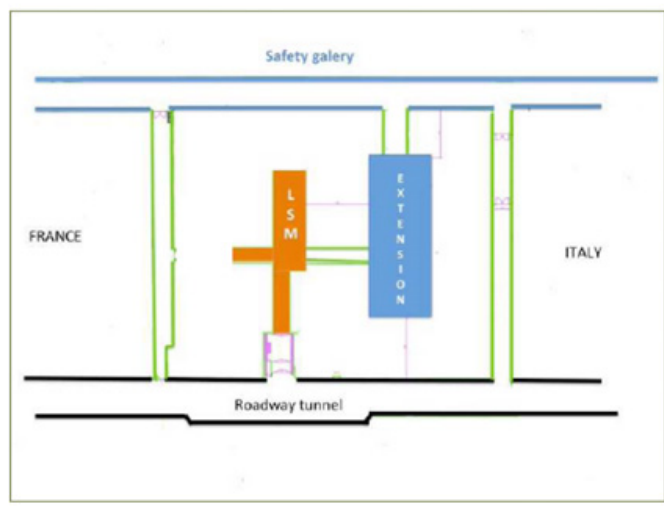

Many avantages to operate both labs, safety, cost,....

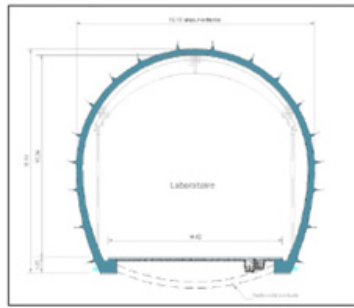

Length : $40 \mathrm{~m}$

High : $16 \mathrm{~m}$

Width : $19 \mathrm{~m}$

Volume : $12000 \mathrm{~m}^{3}$

Total volume $17000 \mathrm{~m}^{3}$

Figure 3. Modane underground laboratory extension [4, slide 19].

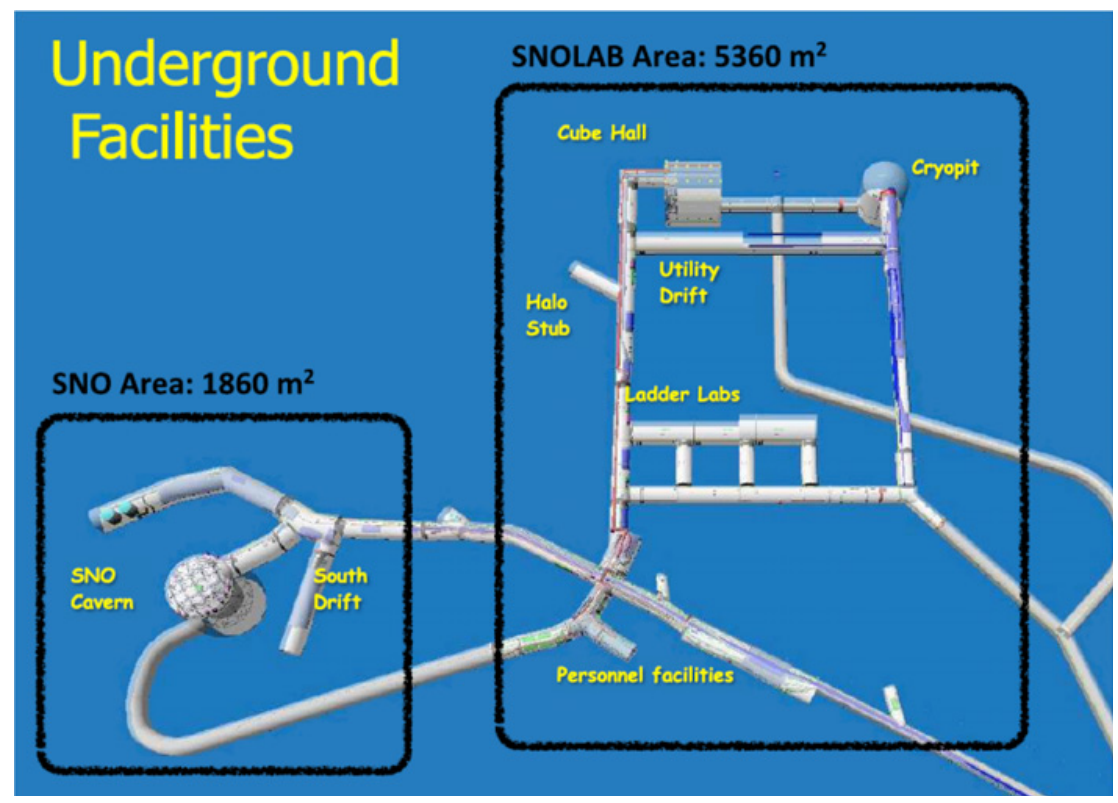

Figure 4. SNOLab space including cryo-pit [5, slide 5].

France's Modane Laboratory Multi-Disciplinary Plan: Figure 3 is the planned expansion at the Modane underground laboratory in France. This space is for multi-disciplinary research to be excavated in 2014-2015 [4].

Canada's SNOLab Facilities: Figure 4 is the completed space in SNOLab in Canada. The cryo-pit is in the shape of a barrel, $18.3 \mathrm{~m}$ in diameter at the waist, $15.2 \mathrm{~m}$ in diameter at the base and top, and $19.8 \mathrm{~m}$ in height [5].

Argentina-Chiles ANDES Laboratory Design: Figure 5 is the design of ANDES Laboratory along the Argentina-Chiles Agua Negra tunnel, which will provide an overburden of 1,750 m [6]. 


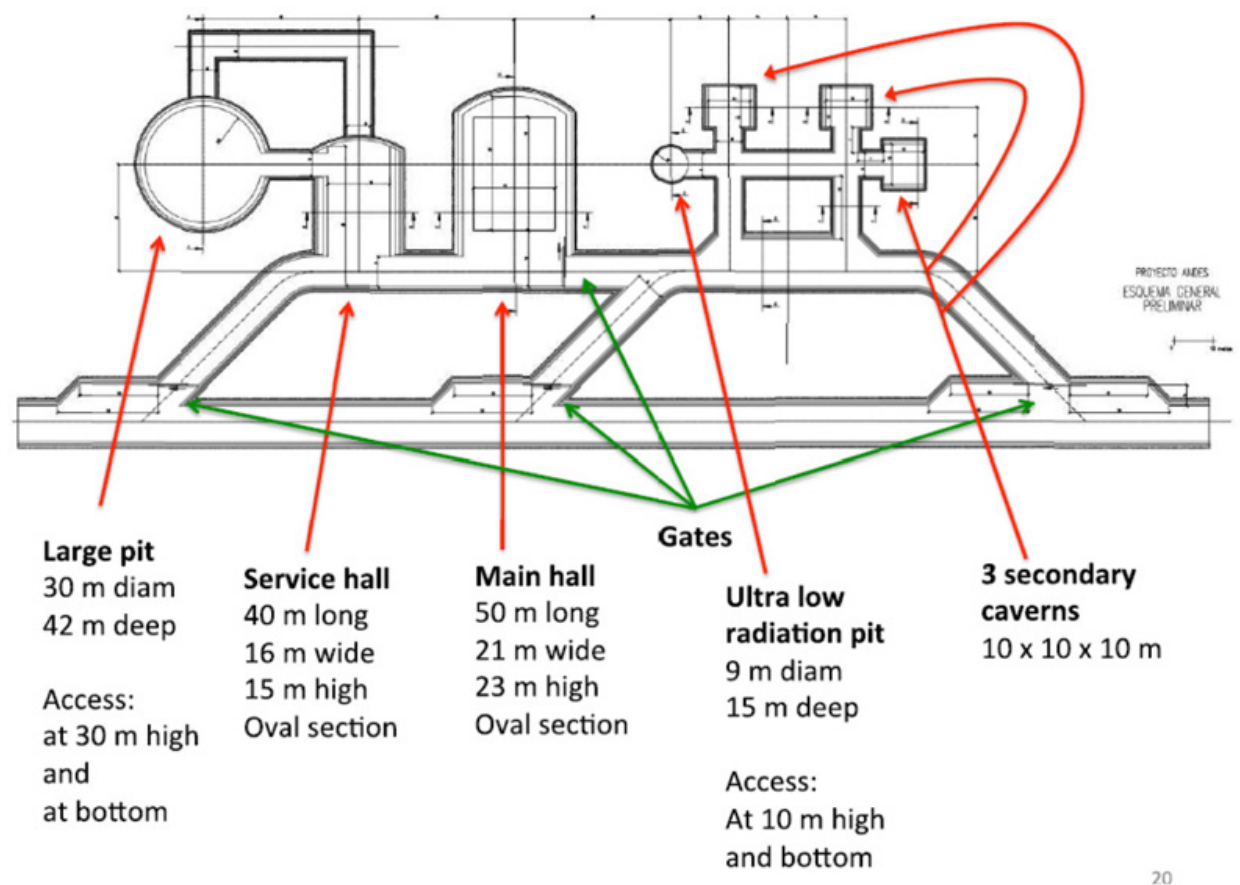

Figure 5. ANDES design [6, slide 20].

\section{Summary}

We present examples indicating that there are spaces planned for large excavations for next generation of physics rare-event experiments and there are also interests in multi-disciplinary studies at depths. Additional description of physics laboratories can be found in [7] and presented in this talk, including ones in India, Italy, Spain, UK and USA.

\section{References}

[1] J.-M. Li, X. D. Ji, W. Haxton, J. S. Y. Wang, The second-phase development of the China JinPing underground laboratory. Physics Procedia, Proceedings for TAUP 2013 Meeting at Asilomar, CA, 9-13 September, 2013 (to be published 2014).

[2] J. Yamatomi, The Hyper-KAMIOKANDE project in the Kimioka mine, Japan, URL Meeting, SINOROCK Symposium, Shanghai, China, 17 June, 2013, 15 slides (2013).

[3] G. Nuijten, LUGANA, URL Meeting, EUROROCK, Wroclaw, 22 September 2013, 30 slides (2013).

[4] F. Piquemal, Activities at Modane underground laboratory, $13^{\text {th }}$ TAUP, Asilomar, CA, USA, 13 September, 2013, 31 slides (2013).

[5] N. Smith, Infrastructure development for underground labs - the SNOLab experience, CJPL-II Town Meeting, $13^{\text {th }}$ TAUP, Asilomar, CA, USA, 8 September, 2013, 29 slides (2013).

[6] C. Dib, ANDES Agua Negra deep experiment site, $13^{\text {th }}$ TAUP, Asilomar, CA, USA, 13 September, 2013, 18 slides (2013).

[7] A. Bettini, New underground laboratories, $13^{\text {th }}$ TAUP, Asilomar, CA, USA, 13 September, 2013, 11 slides (2013). 